\title{
SENTIDOS DE AVALIAÇÃO DA EDUCAÇÃO E NO ENSINO E NO CURRÍCULO NA EDUCAÇÃO BÁSICA ATRAVÉS DOS ESTUDOS PÓS-COLONIAIS LATINO- AMERICANOS
}

Janssen Felipe da Silva ${ }^{1}$

Minhas reflexões sobre os Sentidos de Avaliação na Educação e no Ensino no Currículo da Escola Básica estão alicerçadas nos Estudos Pós-Coloniais Latino-Americanos². Para tanto realizo uma reinterpretação histórica, política e epistêmica da invasão da América, da invenção da Europa e da criação do Mito da Modernidade Colonial-Capitalista ${ }^{3}$ com o objetivo de compreender a geopolítica do conhecimento e da educação e suas repercussões na constituição dos sentidos do Currículo e da Avaliação Escolar.

Friso que os Estudos Pós-Coloniais Latino-Americanos emanam do ideário e das práticas sociopolíticas epistêmicas dos povos indígenas e afrodescendentes desse continente em profundo diálogo com os movimentos de descolonização das demais partes do mundo. Esses Estudos indagam os lócus e os sujeitos historicamente hegemônicos na posição de enunciação, como também

contestam a ego-política do conhecimento e a geopolítica do conhecimento modernas, e lutam contra a herança colonial que se funda na racialização e na racionalização e se sedimenta na colonialidade (SILVA; FERREIRA; SILVA, p. 252, 253).

A discussão que trago tem como premissa que a Europa é uma invenção feita por meio da invasão da denominada hoje de América Latina. A invenção e a invasão deram base para a construção de uma matriz de poder mundial de dominação (MIGNOLO, 2008, 2008a,

\footnotetext{
${ }^{1}$ Pedagogo (FAFIRE) Mestre e Doutor em Educação pelo Núcleo de Pesquisa de Formação de Professores e Prática Pedagógica - UFPE. Professor Adjunto do Centro Acadêmico do Agreste no Núcleo de Formação Docente - UFPE e Professor Permanente dos Programas de Pós-Graduação em Educação do Centro de Educação e do Centro Acadêmico do Agreste da UFPE. Coordenador do Grupo de Estudos Pós-Coloniais e Teoria da Complexidade (CAA/UFPE). E-mail: janssenfelipe@hotmail.com

${ }^{2}$ Sobre o assunto ver Quijano (2005, 2007), Grosfoguel (2007), Dussel (2005), Escobar (2003), Maldonado-Torres (2007), Mignolo (2005, 2011), Walsh (2005, 2007), Martins (2012), entre outros.

${ }^{3}$ Para Oliveira (2010, p. 44), "o mito da modernidade é justificado, em seus aspectos históricos, sociais e epistemológicos, como uma civilização que se autodescreve como mais desenvolvida e superior, e esta obriga a desenvolver os mais "primitivos", "bárbaros", como exigência moral. No mais, o caminho de tal processo deve ser aquele seguido pela Europa, mas se o bárbaro se opuser ao processo civilizador, a práxis moderna deve exercer a guerra justa colonial. O caminho, portanto, é a violência "inevitável" de um "herói" civilizador que salva o índio colonizado e o africano escravizado, além de outras violências no campo epistemológico".
} 
1996). Essa matriz possui seus fundamentos na racialização e na racionalização da sociedade (QUIJANO, 2005) que ocorreram com o advento do colonialismo-colonização do Novo Mundo. Friso que a expressão Novo Mundo é um artifício para negar, apagar e silenciar as histórias dos povos $^{4}$ que habitavam a Abya Yala ${ }^{5}$. O processo de racialização impôs uma classificação humana inicialmente em três raças: brancos, índios e negros. Essa classificação inicial hierarquizou as três raças, tendo como referência quem criou a classificação, no caso o branco europeu enquanto sujeito superior que produz cultura, ciência e civilidade, passível de trabalho intelectual e assalariado. Já as demais raças, os índios enquanto sujeitos inferiores intermediários servis e os negros como sujeitos inferiores escravos, ambos os grupos não passíveis de produzirem cultura, ciência e civilidade. Desta forma, o currículo e avaliação escolar são os lugares historicamente da cultura branca civilizada eurocentrada.

A classificação racial e sua consequente superiorização e inferiorização de camadas da humanidade foi base para que os "brancos civilizados europeus superiores" invadissem o território do dito Novo Mundo e lhe tomassem posse. Além de tomarem posse da terra, deram-se a missão de salvar as almas dos nativos, utilizando-se do artifício da desapropriação dos mesmos de sua condição de sujeito de direito, tornando-os sujeitos servis; como também se valeram da mesma artimanha para que pudessem escravizar os povos oriundos do continente africano, destituindo-os de sua condição de sujeito de direito, transformando-os em sujeitos escravizados. Por isso a história e a cultura dos negros no Brasil no currículo escolar, por exemplo, tem se limitado muitas vezes a história e a cultura dos escravos, reduzindo os negros a essa condição.

Nesse contexto, tanto os índios como os negros não são considerados sujeitos de direitos e thes são impostos a condição de sujeito de favor (LEMOS, 2013). Os sujeitos de direitos prestam um favor aos demais sujeitos quando lhes ensinam, seja em que método for, o que é possível desses indivíduos aprenderem de civilidade. Nessa perspectiva, a condição humana é uma qualidade do homem branco/civilizado/cristão/heterossexual a ser imitada pelos outros subalternizados que jamais podem ser, no máximo podem imitar quem é (o "Eu" eurocentrado). A educação escolar foi e ainda é vista como um favor aos sujeitos não-

\footnotetext{
${ }^{4}$ Por isso que "la historia es un privilegio de la modernidad europea, y para tener una historia hay que dejarse colonizar, es decir, dejarse dominar, voluntariamente o no, por una perspectiva de la historia, la vida, el conocimiento, la economía, la subjetividad, la familia o la religión moldeada por la historia de la Europa moderna, que ha sido adoptada como modelo oficial, con leves modificaciones, por Estados Unidos" (MIGNOLO, 2005, p. 17).

${ }^{5}$ Os Movimentos Indígenas do continente americano usam a expressão Abya Yala como um dos nomes da América. Abya Yala é da língua kuna e significa Terra madura, Terra viva ou Terra em florescimento (PORTO-GONÇALVES, 2009). Outras denominações também são usadas como Tawantinsuyu e Anahuac (MIGNOLO, 2008a).
} 
epistêmicos. Estes sujeitos o que primeiro aprendem na escola é que não-são, por isso que o currículo e a avaliação escolar não selecionam e nem validam suas culturas, e quando trazem algum elemento da cultura dos subalternizados, o fazem por dentro de uma hierarquização em que a cultura do branco eurocentrado sempre ocupa o lugar-tempo de referência tanto no currículo como na avaliação escolar.

Para justificar racionalmente a racialização da sociedade, é criada uma racionalização restrita em que é bem definido quem são os sujeitos, os territórios, as culturas e os conhecimentos tidos como racionais e, consequentemente, também é delimitado quem são os sujeitos, os territórios, culturas e os conhecimentos irracionais. Nessa lógica, são instituídos os sujeitos curriculares: aqueles(as) que têm os elementos de suas culturas selecionados e validados no currículo e na avaliação escolar. Como também é imposto os sujeitos nãocurriculares, aqueles(as) que, ao não terem suas culturas reconhecidas, são culturalmente alienígenas no currículo e na avaliação escolar que se torna para eles(as) alienantes.

Nessa linha de raciocínio, instituem/impõem-se: os sujeitos e os territórios epistêmicos/culturais/civilizados que produzem conhecimentos científicos válidos, culturas de referência e povos civilizados; e os sujeitos e os territórios nãoepistêmicos/culturais/civilizados que não produzem conhecimentos válidos, não possuem cultura de referência e povos não civilizados. Há, então, uma divisão racial do conhecimento, da cultura e da civilização e da educação escolar por meio da classificação e da hierarquização dos seres humanos e de seus territórios. Por isso compreendemos que o currículo e a avaliação escolar modernos são racializados, trazem consigo as marcar da racialização da sociedade. Assim, currículo e avaliação escolar oficiais foram historicamente colonizados, constituídos através das lógicas da racialização e da racionalização eurocêntrica.

A classificação e a hierarquização inaugurada com o colonialismo-colonização é transformada em uma matriz de poder do sistema mundo capitalista-moderno-colonial. O que foi inventado na América é instituído enquanto modelo de dominação do mundo pelos europeus dos países hegemônicos. Desta forma, o capitalismo não foi possível apenas pela exploração das riquezas naturais e da servidão-escravização dos índios e dos negros respectivamente, mas pela invenção/imposição de uma nova forma de organização da sociedade que deixa de ser local e passa a ser mundial.

Assim, a nova face da globalização da humanidade, moderna/capitalista/colonial, é a determinação por uma cosmovisão local enquanto universal. Para tanto, é necessário uma violenta assepsia epistêmica e cultural da sociedade. O OUTRO é instituído enquanto o anti- 
modelo que não possui as condições de ser, de produzir e de viver civilizadamente sem a ajuda (favor) DAQUELE que É. O OUTRO vive a condição de empréstimo, ao não ser e não ter, somente cabendo-LHE reconhecer-se como o NÃO-SER e obedecer ÀQUELE que É. Por isso, por exemplo, o argumento do índio e do negro serem considerados indolentes e preguiçosos justifica o uso da força física para corrigi-los e aproximá-los de uma dita vida civilizada. Aproximá-los dessa dita vida civilizada somente é possível se os mesmos aceitarem a sua condição de seres inferiores que precisam ser ajustados custe o que custar. Nessa perspectiva, a escola tem um papel fundamental de ensinar, através da relação currículo, didática e avaliação, as posições de cada um na sociedade racializada.

Esse processo é o berço da geopolítica do conhecimento moderno, é o lastro de sua organização política, dando sustentabilidade argumentativa a uma matriz de poder mundial. Matriz essa que tem continuidade com o fim das colônias principalmente nos séculos XIX e XX. Desta forma, a geopolítica do conhecimento é constituída por meio da barbárie da Europa sobre os povos da denominada América Latina e dos africanos brutamente sequestrados. Essa geopolítica do conhecimento é a base sólida da cosmovisão eurocentrada que condiciona o sistema escolar moderno, seu currículo e sua avaliação.

A independência das colônias não representou o término da matriz de poder que se constitui com o colonialismo-colonização, mas a sua reconfiguração através da Colonialidade, a herança colonial. Nessa geopolítica do conhecimento moderno-colonial há a instituição de elementos da sociedade como naturalmente superiores, um exemplo é o que são denominados de idiomas e de dialetos, de cultura e de folclore, de religião e de seita, de fé e de superstição, de erudito e de popular, de educação formal e informal. Entre os idiomas, os que são de referência e os que são periféricos. Obviamente que os idiomas de referência pertencem aos países colonizadores e os dialetos aos povos dos territórios colonizados. Igualmente se institui o que é religião, seita e misticismo. A religião de referência é o cristianismo na versão da cristandade com suas variações, mas sob a hegemonia do Catolicismo Romano. As seitas representam a dimensão transcendente dos povos colonizados, por isso, por exemplo, que o Candomblé (negro) e a Jurema (índio) até hoje sofrem com a discriminação social e a perseguição religiosa. A educação que se dá nas comunidades e nos movimentos sociais é tida como educação informal, fora dos "padrões" de exigência do sistema escolar oficial.

Nessa linha de raciocínio, a Colonialidade é 
un patrón de poder que emergió como resultado del colonialismo moderno, pero que en vez de estar limitado a una relación formal de poder entre dos pueblos o naciones, más bien se refiere a la forma como el trabajo, el conocimiento, la autoridad y las relaciones intersubjetivas se articulan entre sí, a través del mercado capitalista mundial y de la idea de raza. Así, pues, aunque el colonialismo precede a la colonialidad, la colonialidad sobrevive al colonialismo. La misma se mantiene viva en manuales de aprendizaje, en el criterio para el buen trabajo académico, en la cultura, el sentido común, en la auto-imagen de los pueblos, en las aspiraciones de los sujetos, y en tantos otros aspectos de nuestra experiencia moderna. En un sentido, respiramos la colonialidad en la modernidad cotidianamente (MALDONADO-TORRES, 2007, p. 131).

A Colonialidade representa o lado oculto da modernidade, esta tendo o papel de ser o estandarte simbólico da ordem e do progresso, da emancipação dos seres humanos das trevas medievais e da selvageria dos territórios colonizados. A modernidade passa a ser a expressão da culminância do progresso humano, tecnológico, econômico, político e civilizatório. Contudo, a modernidade é a história "triunfante" local de certos países europeus que é transfigurada como referência para reescrever a "história universal". Para que a história local de certos países europeus se transforme "magicamente" em base da história universal é preciso apagar as histórias dos povos brutalmente colonizados, subalternizados e silenciados: essa é a função fundante da Colonialidade. Podemos dizer que a Colonialidade é o capataz e a força motriz da Modernidade. Esta tem o papel argumentativo que consegue hegemonizar-se por meio das violências geradas material e simbolicamente pela Colonialidade. Se compararmos com o currículo escolar, podemos dizer que os conteúdos de ensino declarados representam a modernidade escolar; já os valores, as crenças, os costumes eurocentrados implícitos e algumas vezes explícitos no currículo como a negação da cultura dos povos subalternizados são expressões da Colonialidade.

A Colonialidade, assim, "é ferramenta útil ao capitalismo por seu poder de penetração tanto nas estruturas de poder da sociedade como na vida cotidiana dos sujeitos" (SILVA; TORRES; LEMOS, 2012, p. 414). A Colonialidade tem sua eficácia ao se alastrar nas relações do dia a dia nas várias dimensões da vida: racial, étnica, de gênero, sexual, geracional, de classe, ecológica, etc. Nessa direção, a Colonialidade visa o "controle do conhecimento, da subjetividade dos sujeitos coloniais, do gênero, da sexualidade mediante o modelo de família cristã-colonial, latifundiária e burguesa, e da normativa sexual" (MIGNOLO, 2008a, p. 242). A Colonialidade, desta maneira, precisa do controle sobre o currículo, a didática e a avaliação 
escolar para conformação das identidades colonizadoras e colonizadas. Por isso o sistema escolar é um latifúndio epistêmico, cultural, político e social da elite burguesa.

Quijano (2007) destaca três eixos constitutivos da natureza da Colonialidade, são eles: do Poder, do Ser e do Saber. A Colonialidade do Poder é a imposição da classificação e da hierarquização racial da sociedade enquanto condição natural dos sujeitos e de seus territórios. Essa classificação e hierarquização racial se estendem às relações de gênero, de trabalho, de religião, de educação, ecológica, entre outras. Segundo Silva, Torres e Lemos,

A colonialidade do poder se refere aos processos de dominação por meio da inferiorização cultural de um povo frente a um padrão préestabelecido de organização social, como exemplo podemos frisar a relação imposta de subordinação histórica dos povos das áreas rura is em relação aos povos urbanos (2012, p. 414).

Assim se define, com uma conotação de naturalidade, os vários tipos de classificação e de exploração necessários e alicerçantes da sociedade moderna capitalista: patriarcado classificação-exploração de gênero; urbanocentrismo - classificação-exploração territorial; heterocentrismo - classificação-exploração sexual; etnocentrismo - classificação-exploração étnica; eurocentrismo - classificação-exploração epistêmica; entre outras classificaçõesexplorações. Vejo que o currículo e a avaliação escolar assumem papel fundamental de concretização dessas hierarquias no território escolar: tanto na organização do sistema escolar (escolas de referências e não-referências) como na própria organização da escola (turmas A, B, C, D...) e da sala de aula (os que sentam nas primeiras fileiras, nas do meio e nas do fim). A lógica da classificação-explocação também se manifesta na organização currículo na hierarquia entre as áreas e disciplinas, no tempo destinado a cada disciplina de acordo com seu prestígio ou não-pretígio no currículo (das disciplinas da matemática e da língua considerada materna até chegar às disciplinas de história, de arte...).

A Colonialidade do Ser é a interiorização da condição de inferioridade pelos povos subalternizados e a aceitação da condição de superioridade dos povos colonizadores. Posso comparar, em certa medida, com o que Freire (2005) denomina de Hospedeiro do Opressor. A Colonialidade do Ser é um fenômeno individual e coletivo, tanto atinge o sujeito como o grupo ao qual pertence, com isso, essa Colonialidade tem uma falsa legitimidade, alcançando as subjetividades em diversos níveis de (auto) percepção de valores socioculturais e de referências ontológicas. Essa dimensão da Colonialidade é a construção de uma cultura 
naturalizada de classificação e de hierarquização dos sujeitos que é incorporada pelos grupos e seus respectivos membros.

Para Mignolo,

la colonización del ser consiste nada menos que en generar la idea de que ciertos pueblos no forman parte de la historia, de que no son seres. Así, enterrados bajo la historia europea del descubrimiento están las historias, las experiencias y los relatos conceptuales silenciados de los que quedaron fuera de la categorías de seres humanos, de actores históricos y de entes racionales (2005, p. 30).

A Colonialidade do Ser tem uma relação profunda com o currículo, este compreendido como território identitário. O currículo é o principal artefato cultural, político, social, epistêmico e pedagógico do sistema escolar para a construção das identidades desejadas, sejam identidades de comando ou comandadas. E a Colonialidade do Ser precisa da avaliação escolar como processo de validação das identidades e das suas respectivas cosmovisões.

A Colonialidade do Saber é a determinação de uma única epistemologia válida: a eurocêntrica que sustentou e sustenta as ciências modernas e suas derivações como é o caso dos currículos escolares, ou melhor, da seleção, da organização e da materialização dos conteúdos escolares (conhecimentos, valores, crenças, costumes, atitudes). A Colonialidade do Saber é fundamental para justificar a superioridade dos colonizadores e inibir/impedir a crítica da condição de superioridade e dos mecanismos de controle social, epistêmico e civilizatório. Esse eixo da Colonialidade faz com que o subalternizado além de não ser considerado sujeito de direito também não possa assumir a condição de sujeito epistêmico, enquanto aquele que tem a prerrogativa de produzir conhecimento válido. Por isso que os elementos culturais dos povos subalternizados não são dignos de estarem presentes no currículo em posição de prestígio: a sua cultura é folclorizada; os seus mitos se tornam lendas; a sua arte vira artesanato. Com isso a dinâmica de avaliação escolar é calcada em Hierarquias de Excelências (PERRENOUD, 1999) que validam hierarquicamente saberes e identidades.

Esses eixos da Colonialidade são articulados para a manutenção da matriz de poder instituída com a invasão/invenção da América e da invenção da Europa. Algumas ações são bem evidentes nesse enredo que deu e dá sustentação ao Mito da ModernidadeColonialidade. Destaco dessas ações: a) a reinvenção da humanidade através da racialização; b) a reinvenção da geografia mundial com a criação do Novo Mundo e dos Estados-Nação; c) a 
criação de uma noção de ordem e de progresso que coloca a Europa como modelo de civilização e silencia e nega as histórias e a diversidade de civilizações que habitavam territórios não-europeus; d) a construção arbitrária do ideário da universalidade por meio da localidade de um determinado território da Europa; e) a articulação de várias formas de trabalho (servil, escravo e assalariado) em função dos interesses do capitalismo; f) a fetichização do capital; g) a exploração da natureza associada aos ares das conquistas; h) a criação da educação escolar moderna como prerrogativa e exigência natural para a vida em sociedade.

Simultâneo à reinvenção do mundo por meio da Colonialidade com centralidade no mundo europeu, os mundos outros sofreram da ostensiva tentativa de apagar suas histórias, ou seja, somente era possível o Velho Mundo e, mais especificamente, os países europeus hegemônicos a posição de sujeitos históricos e protagonistas em levar civilidade possível para o resto do planeta. Por isso que os sujeitos históricos eurocentrados são os sujeitos curriculares. Os territórios do norte global são os lócus culturais civilizados dos quais se extraem os elementos culturais de referência para a constituição do currículo a ser validado na avaliação escolar.

Assim, a racialização dos sujeitos se estendia aos seus territórios. Pertencer a determinado grupo social e territorial já desautorizavam os sujeitos de fazer e de escrever suas histórias, de produzir cultura e civilidade e de serem sujeitos curriculares, cabendo apenas a se sujeitarem ao currículo escolar. Por consequência, quaisquer vanguardismos ou protagonismos somente eram e são possíveis advindos da Europa e de sua extensão (Estados Unidos da América). Dos demais territórios, os não-lugares, somente atitude de barbárie poderia se esperar, até mesmo se posicionar contra a Colonialidade representava uma postura anticivilizada, a exemplo da formação dos quilombos no Brasil, seus membros eram considerados revoltados, incultos, irracionais, hereges e cruéis. Por isso a resistência histórica do sistema escolar em incorporar os líderes e heróis negros, indígenas, femininos no currículo escolar em posição de prestígio.

Dessa forma, vai se constituindo também uma geopolítica moderno-colonial da educação, uma espécie de divisão mundial da educação, ou melhor, do sistema educacional. Não é por acaso que falamos de "educação de primeiro mundo" como sinônimo de educação de qualidade. É criado um imaginário que a referência de educação escolar está nos países europeus e nos Estados Unidos. No dito resto do mundo, a educação escolar deve reproduzir a lógica cultural, política e epistêmica dos países centrais, contudo, com pouca eficácia. Não é preciso uma "educação de primeiro mundo" nos demais mundos. É necessária apenas uma 
educação escolar que ensine a apagar as histórias e a descredenciar as epistemologias locais e afirmar epistemologias hegemônicas fundadas no eurocentrismo.

Destaco ainda que na mesma escola há forças Decoloniais que, ao longo do tempo, vêm se estruturando e evidenciando as contradições da Colonialidade. Exemplos das resistências e das proposições (Decolonialidades) são: a luta pela educação das relações étnico-raciais que tem se intensificado nos últimos anos; a luta dos indígenas e dos povos do campo por uma educação específica e diferenciada, entre outras. Desta forma, a escola é território de Diferenças Coloniais, mais do que de diferenças culturais. Ou seja, a questão da Colonialidade sobre o currículo e a avaliação escolar não é meramente a presença ou não de determinadas culturas no currículo, mas as lógicas estruturantes que os organizam e materializam. Assim, a Diferença Colonial na escola, no currículo e na avaliação expressa o conflito entre cosmovisões que em tensão se reconfiguram historicamente.

Chamo atenção à complexidade que envolve a tensão entre Colonialidade $e$ Decolonialidade no currículo e na avaliação escolar. Não por um lado, não há uma Colonialidade Pura que atravessou o tempo e o espaço, por outro lado, também não existe uma Decolonialidade Intacta que resistiu ao tempo e ao espaço. A Colonialidade e a Decolonialidade se fazem e refazem mutuamente, cada uma delas trazem em si elementos da outra que estão presentes no cotidiano escolar mais especificamente.

Saliento ainda que existem níveis da divisão política e social da educação. Há uma educação para a elite mundial pertencente do primeiro mundo e outra para as elites dos demais países; uma educação para a periferia do mundo localizada nos países centrais e outra para as periferias localizadas nos países não-centrais. A diferenciação da educação escolar e, consequentemente, do seu currículo não é para atender aos interesses locais, mas, ao contrário, para atender aos desejos das elites locais, interlocais e "mundiais".

Mesmo assim, nos escombros da modernidade, as "periferias" do mundo moderno, os povos historicamente subalternizados se refizeram na urgência da sobrevivência. A cultura e a educação têm um papel imprescindível na resistência às imposições coloniais e na proposição de formas outras de vida. A resistência e a proposição fronteiriça constituíram os processos de Decolonialidade. A Decolonialidade em tensão com a Colonialidade gerou e gera a Diferença Colonial. Essa Diferença é a prova viva do não total sucesso dos projetos modernocoloniais de sociedade, principalmente de educação escolar moderna e de seu respectivo currículo e avaliação. 
$\mathrm{Na}$ Diferença Colonial podem ser gerados Pensamentos ou Epistemologias de Fronteiras através da Desobediência Epistêmica e Civil. Os Pensamentos ou Epistemologias de Fronteira são as bases das pedagogias críticas e pós-críticas da América Latina no enfretamento da geopolítica da educação moderno-colonial. Os Pensamentos ou Epistemologias de Fronteira possuem o papel de, segundo Grosfoguel,

Ao invés de rejeitarem a modernidade para se recolherem num absolutismo fundamentalista, as epistemologias de fronteira subsumem/redefinem a retórica emancipatória da modernidade a partir das cosmologias e epistemologias do subalterno, localizadas no lado oprimido e explorado da diferença colonial, rumo a uma luta de libertação descolonial em prol de um mundo capaz de superar a modernidade eurocentrada. Aquilo que o pensamento de fronteira produz é uma redefinição/subsunção da cidadania e da democracia, dos direitos humanos, da humanidade e das relações econômicas para lá das definições impostas pela Modernidade europeia (2010, p. 480-481).

Um currículo e uma avaliação escolar decoloniais não é a rejeição da cosmovisão do Norte Global, mas o acirramento do diálogo entre ela (cosmovisões do Norte Global) e as demais cosmovisões do Sul Global, tomando esta última como referência do diálogo. Volto afirma que essas cosmovisões não são em si mesmas, não são puras, são frutos da tensão gerada pelo conflito permanente entre elas. As cosmovisões carregam elementos de outras cosmovisões ressignificando-os a partir de interesses inúmeros e muitas vezes difusos.

Nessa lógica, os Pensamentos ou Epistemologias de Fronteira são sinais da possibilidade de enfrentamento da geopolítica do conhecimento e da educação modernocolonial, mas sem cair no sectarismo da negação da modernidade-colonialidade, ao contrário, travando um diálogo conflitivo e propositivo.

Os Pensamentos ou Epistemologias de Fronteira constituem o mosaico do Pensamento Decolonial. E ressalto que

la genealogía del pensamiento decolonial es pluriversal (no universal). Así, cada nudo de la red de esta genealogía es un punto de despegue y apertura que reintroduce lenguas, memorias, economías, organizaciones sociales, subjetividades, esplendores y miserias de los legados imperiales. La actualidad pide, reclama, un pensamiento decolonial que articule genealogías desperdigadas por el planeta y 
ofrezca modalidades económicas, políticas, sociales y subjetivas "otras" (MIGNOLO, 2005, p. 45).

Na relação entre a geopolítica moderno-colonial do conhecimento e da educação escolar herdadas da modernidade há de se ter um posicionamento não de reforma do pensamento moderno em suas variáveis, mas, sobretudo, de sua superação e transformação em dinâmicas ambivalentes de mudanças e de permanências. Novas geopolíticas do conhecimento e da educação exigem "aprender a desaprender" (MIGNOLO, 2008), desatar os nós da Modernidade-Colonialidade para tecer projetos outros de sociedade.

Uma possibilidade de novas geopolíticas do conhecimento e da educação escolar é questionar a ideia de Estado Nacional Uni-identitário. Primeiro, o continente latino americano é constituído de inúmeros povos que não estão circunscritos nas fronteiras impostas pelo eurocentrismo político. Segundo, os países latino-americanos são invenções europeias e não uma reivindicação dos povos originários desse continente. Isto é, os países latino-americanos são criados desde as colônias para atender aos interesses europeus ${ }^{6}$. O conhecimento, a educação e mais precisamente o currículo e a avaliação escolar vêm servindo no passar dos tempos para naturalizar as fronteiras e as identidades nacionais impostas. A reinvenção da geopolítica do conhecimento e da educação requer a construção simultânea de Estados Plurinacionais ${ }^{7}$ que constituem as inúmeras identidades e compõem o mosaico dos países latino-americanos.

Dessa maneira, o Estado Plurinacional

rompe com a uniformização do estado nacional que possibilitou o desenvolvimento do capitalismo moderno. Esta ruptura, que pode ser revolucionária, se apresenta na aceitação constitucional de diversos direitos de propriedade e de diversos direitos de família, assim como a admissibilidade de tribunais para resolver estas questões no âmbito de cada comunidade étnica (MAGALHÃES, 2008, p. 202).

\footnotetext{
${ }^{6}$ Os Estados Nacionais da América Latina foram construídos pelos descendentes dos colonizadores europeus para atender a seus interesses. São Estados forjados por uma minoria constituída das elites econômicas e militares da época. Assim, os povos originários desse continente e os povos africanos sequestrados ficaram de fora da construção e da atenção desses Estados.

${ }^{7}$ O Estado Plurinacional e Pluri-identitário compreende que a democracia participativa é base da democracia representativa e garante constitucionalmente as várias formas de família e da economia de acordo com os valores tradicionais dos inúmeros grupos sociais presentes no país.
} 
A reinvenção dos Estados, tomando como referência, principalmente, as identidades coletivas historicamente subalternizadas, tem rebatimento direto na educação escolar, em destaque nos currículos escolares em várias dimensões inter-relacionadas.

A primeira dimensão é a teórica, as concepções de currículos foram produzidas no Norte Global ${ }^{8}$ e universalizadas. Ao Sul Global coube o papel de reproduzi-las e adaptá-las. Quando falo de teorias curriculares me refiro aqui tanto às Liberais como às Críticas e PósCríticas, sendo estas últimas cunhadas no seio do que se denomina de Pós-Modernidade. Todas elas tomam as experiências do Norte Global como referência universal para produzir teorias curriculares. Nessa dimensão é fundamental tomar as experiências do Sul Global como fonte de produção de teorias curriculares através de epistemologias outras, dos Pensamentos ou Epistemologias de Fronteira. Esta minha afirmação não tem a pretensão de descredenciar as Teorias Críticas ou Pós-Críticas, mas evidenciar a diferença que existe entre elas e a perspectiva Pós-Colonial Latino-Americana.

A segunda dimensão refere-se às políticas curriculares fundadas na ideia de política de identidade e não de identidade na política (MIGNOLO, 2008). Com os avanços na discussão sobre currículo, a ideia de diferença e de diversidade ganha força. Os Estudos Culturais e PósEstruturalistas são fundamentais no debate interno do Pensamento Eurocêntrico na revitalização da Europa enquanto lócus de enunciação das Teorias Pós-Críticas. Nesse sentido, a Pós-Modernidade, segundo Mignolo, é uma crítica interna à Modernidade. Essa crítica interna à Modernidade coloca em pauta questões de gênero, de raça, de etnia, de território, de geração, etc. Questões relacionadas ao que se passou a denominar de diversidade ou diferença. Entretanto, as experiências do Sul Global não são tidas como referência para a produção dessas teorias.

A discussão advinda do eurocentrismo está mais relacionada à política de identidade, ao incorporar na política curricular, por exemplo, as identidades dos povos ou grupos sociais historicamente subalternizados. Contudo, é o Estado que define na tensão o que é a identidade de cada minoria, o debate na construção dessa política não tem como lócus de enunciação os povos e os grupos subalternizados. É o que Walsh $(2010,2008)$ nomeia de oficialização da diferença. Essa oficialização não tem a pretensão de mudar as estruturas de poder do Estado e os status quo de determinados grupos sociais. É uma incorporação da diferença com o intuito da manutenção da matriz de poder moderno-colonial. Por exemplo, a incorporação da cultura e da história africana e afrodescendente e indígena na política

\footnotetext{
${ }^{8}$ Sobre a discussão entre o Norte e o Sul Global ver Santos (2013).
} 
curricular, de início, não é garantia de mudança substancial, porque a forma de tratá-las pode continuar tendo como referência o eurocentrismo. Isto é, o Estado Nacional Uni-identitário dizer o que é história e cultura indígena e africana e afrodescendente sem considerar as cosmovisões africanas e indígenas.

Em outras palavras,

As marcas da presença da herança colonial que perpassa a nossa sociedade e, consequentemente, os currículos escolares representam, de um lado, o que não foi ensinado e, consequentemente, o que não sabemos sobre História e Cultura da África, dos Afro-Brasileiros e dos Povos Indígenas. Por outro lado, o pouco que é ensinado dessas Histórias e Culturas é realizado pelo prisma do imaginário europeu. Por isso, o currículo escolar quando não silencia as Histórias e Culturas outras, trata-as sob a visão imperialista e asséptica da lógica eurocentrada (FERREIRA; SILVA, 2013, p. 27).

Os Estudos Pós-Coloniais, em especial, os Latino-Americanos partem de outro entendimento: oficializar a diferença não é suficiente. Aprender com as experiências dos povos indígenas e das comunidades afrodescendentes do continente Americano, tomando-as como lócus de enunciação epistêmica e política, é um caminho possível para discutir identidade na política. Esses povos e comunidades devem assumir a condição de sujeito de direito e epistêmico e serem referência na constituição da política. Essa superação da oficialização da diferença é possível se o DNA do Estado Nacional Uni-Identitário for questionado, problematizado e transformado. A identidade na política pressupõe a própria mudança na identidade do Estado Nacional Uni-Identitário, colocando em tela o projeto de Estado Plurinacional, Pluri-identitário e de Sociedade Intercultural. Nesse prisma, há necessariamente mudanças nas estruturas de poder moderno-colonial.

Ressalto que tomar os territórios e sujeitos historicamente subalternizados enquanto sujeito de direito e epistêmicos não é, por um lado, naturalizar a ideia de quaisquer discursos ou experiências do Sul Global como novas verdades; nem, por outro lado, demonizar quaisquer discursos ou experiências oriundas do Norte Global.

Pensar a geopolítica moderno-colonial do conhecimento e da educação a partir da Decolonialidade requer pensar-agir relacionando justiça social, justiça epistêmica e justiça cognitiva na construção de projetos societais decoloniais. Pensar numa geopolítica do conhecimento e da educação decolonial requer novos ensaios e enredos teóricos que sejam 
construídos através das reflexões analíticas sobre as experiências vividas no Sul Global. No caso específico da América Latina, falo das experiências das lutas dos movimentos indígenas, negros, campesinos, das mulheres, entre outras.

Para pensar e agir na urgência da ruptura com os sistemas educacionais que ainda são predominantemente eurocentrados é necessário articular a construção dos Estados Plurinacionais à compreensão do continente Latino-Americano como uma comunidade de destino. Essa comunidade de destino (MARTINS, 2012) se faz quando a população latina tomar consciência dos processos de dominação que se iniciaram com a sua invasão e continuam com suas independências. Essa tomada de consciência possibilita produzir conhecimento pluriversitário sobre essas experiências de dominação, utilizando-se das Desobediências Epistêmicas, dos Pensamentos e Epistemologias de Fronteira e construindo geopolítica decolonial do conhecimento e da educação.

Desta maneira, pensar-fazer um currículo e uma avaliação escolar no sentido da Decolonialidade é um desafio dialógico que nos impulsiona a estreitar as relações entre universidade-escola e as comunidades e os povos originários, afrodescendentes, campesinos, etc. na construção de práxis de pesquisa, de ensino e de extensão que nos ensine a aprender outras cosmovisões.

Termino afirmando que os sentidos do currículo e da avaliação escolar ainda são profundamente colonizados, sendo assim fundamental aprender com os povos indígenas e afrodescendentes como estes vêm pensando e propondo a educação, o currículo e avaliação escolar. Pesquisar as comunidades indígenas e quilombolas para aprender o que estas comunidades têm produzido através da interculturalidade enquanto projeto político e prática sociopolítica, epistêmica e pedagógica de enfretamento.

\section{REFERÊNCIAS}

DUSSEL, E. Europa, modernidade e eurocentrismo. In: LANDER, E. (Org.). A Colonialidade do Saber, Eurocentrismo e Ciências Sociais: perspectivas latino-americanas. Buenos Aires: CLACSO, 2005, p. 55-70.

ESCOBAR, A. Mundos y conocimientos de otro modo: el programa de investigación de modernidad/colonialidad latinoamericano. Tabula Rasa. Colombia, $\mathrm{n}$ 0 01, enero-diciembre, 2003, p. 51-86.

FERREIRA, M. G.; SILVA, J. F. Perspectiva Pós-Colonial das relações étnico-raciais nas práticas curriculares: conteúdos selecionados e silenciados. Revista Teias, São Paulo, v. 14, n. 33, dezembro, 2013, p. 25-43: Dossiê Especial. 
FREIRE, P. Pedagogia do Oprimido. 49ạ reimpressão. Rio de Janeiro: Paz e Terra, 2005.

GROSFOGUEL, R. Para descolonizar os estudos de economia política e os estudos pós-coloniais: transmodernidade, pensamento de fronteira e colonialidade global. In. SANTOS, B. S.; MENESES, M. P. (Org.). Epistemologias do Sul. São Paulo: Cortez, 2010, pp. 455-491.

GROSFOGUEL, R. Descolonizando los universalismos occidentales: el pluri-versalismo transmoderno decolonial desde Aimé Césaire hasta los zapatistas. In: CASTRO-GÓMEZ, S.; GROSFOGUEL, R. (Org.). El Giro Decolonial: reflexiones para una diversidad epistémica más allá del capitalismo global. Bogotá: Siglo del Hombre Editores; Universidad Central, Instituto de Estudios Sociales Contemporáneos y Pontificia Universidad Javeriana, Instituto Pensar, 2007, p. 63-78.

LEMOS, G. T. Os Saberes dos povos campesinos tratados nas práticas curriculares de escolas localizadas no território rural de Caruaru-PE 2013. 183f. Dissertação (Mestrado em Educação) Centro de Educação, Universidade Federal de Pernambuco, Recife, 2013.

MAGALHÃES, J. L. Q. Plurinacionalidade e cosmopolitismo: a diversidade cultural das cidades e diversidade comportamental nas metrópoles. Rev. Fac. Direito UFMG, Belo Horizonte, n. 53, p. 201-216, jul./dez. 2008.

MALDONADO-TORRES, N. Sobre la colonialidad del ser: contribuciones al desarrollo de un concepto. In: CASTRO-GÓMEZ, S.; GROSFOGUEL, R. (Org.). El Giro Decolonial: reflexiones para una diversidad epistémica más allá del capitalismo global. Bogotá: Universidad JaverianaInstituto Pensar, Universidad Central-IESCO: Siglo del Hombre Editores, 2007. p. 127-167.

MARTINS, P. H. La Decolonialidad de América Latina e la heterotopía una comunidad de destino solidária. Buenos Aires: Fundación CICCUS; Estudios Sociológicos Editora, 2012.

MIGNOLO, W. Herencias coloniales y teorías postcoloniales. In: GONZÁLES STEPHAN, B. Cultura y Tercer Mundo: Cambios en el Saber Académico. Venezuela: Nueva Sociedad, 1996. pp. 99136.

MIGNOLO, W. Cambiando las Éticas y las Políticas del Conocimiento: La Lógica de la Colonialidad y la Postcolonialidad Imperial. 2005. Disponível em: www.tristestopicos.org. Acesso em 09/08/2011.

MIGNOLO, W. Desobediência Epistêmica: a Opção Descolonial e o significado de Identidade em Política. Cadernos de Letras da UFF - Dossiê: Literatura, língua e identidade, Rio de Janeiro, no 34, 2008, p. 287-324.

MIGNOLO, W. Novas reflexões sobre a "idéia da américa latina": a direita, a esquerda e a opção descolonial. In.: CADERNO CRH, Salvador, v. 21, n. 53, p. 239-252, Maio/Ago. 2008a.

MIGNOLO, W. Historias Locales/Diseños Globales: Colonialidad, conocimientos subalternos y pensamiento fronterizo. 1aㅡ reimpresión. Madrid: Akal, 2011.

OLIVEIRA, L. F. História da África e dos Africanos na Escola: as perspectivas para a formação dos professores de História quando a diferença se torna obrigatoriedade curricular. 2010. Tese (Doutorado em Educação) - Pontifícia Universidade Católica do Rio de Janeiro, Rio de Janeiro, 2010. 
PERRENOUD, Philippe. Avaliação: da excelência à regulação das aprendizagens: entre duas lógicas. Porto Alegre : ArtMed, 1999.

PORTO-GONÇALVES, C. W. Entre América e Abya Yala - tensões de territorialidades. Desenvolvimento e Meio Ambiente, n. 20, jul./dez. 2009. Editora UFPR, p. 25-30.

QUIJANO, A. Colonialidade do Poder, Eurocentrismo e América Latina. In: LANDER, E. (Org.). A Colonialidade do Saber: Eurocentrismo e Ciências Sociais. Trad. Júlio César Casarin Barroso Silva. 3. ed. Buenos Aires: CLACSO, 2005, p. 227-278.

QUIJANO, A. Colonialidad del Poder y Clasificación Social. In: CASTRO-GÓMEZ, S.; GROSFOGUEL, R. (Org.). El Giro Decolonial: reflexiones para una diversidad epistémica más allá del capitalismo global. Bogotá: Siglo del Hombre Editores; Universidad Central, Instituto de Estudios Sociales Contemporáneos y Pontificia Universidad Javeriana, Instituto Pensar, 2007, p. 93-126.

SANTOS, B. S. Descolonizar el saber, reinventar el poder. Montevideo: Ediciones Trilce Extensión universitaria Universidad de la República, 2010.

SANTOS, B. S. Um Discurso sobre as ciências. 10.ed. Porto: Edições Afrontamento, 1998.

SILVA, J. F.; TORRES, D. X.; LEMOS, G. T. Educação do Campo: a luta dos Movimentos Sociais Campesinos por uma Educação Escolar Específica e Diferenciada. In. Revista Pedagógica UNOCHAPECÓ - Ano-15 - n. 28 vol. 01 - jan./jun. 2012, p. 407-436.

SILVA, J. F.; FERREIRA, M. G.; SILVA, D. J. Educação das Relações Étnico-Raciais: um caminho aberto para a construção da educação intercultural crítica. Reveduc UFSCar, São Carlos, v. 7, n. 1 , maio de 2013, p. 248-272.

WALSH, C. La Educación Intercultural en la Educación. Peru: Ministério de Educación. (documento de trabalho), 2005.2 Disponível em: http://www.unicef.org/peru/ files/Publicaciones/Educacionbasica/peru educacion intercultu ralidad.pdf. Acesso em 14/12/2011.

WALSH, C. Interculturalidad, Plurinacionalidad y Decolonialidad: Las Insurgencias PolíticoEpistémicas de Refundar el Estado. Tabula Rasa. Bogotá, Colombia, No.9: 131-152, juliodiciembre 2008.

WALSH, C. Interculturalidad crítica y educación intercultural. In: VIAÑA, J.; TAPIA, L.; WALSH, C. Construyendo Interculturalidad Crítica. 3. ed. La Paz, Bolivia: CAB Instituto Internacional de Integración del Convenio Andrés Bello, 2010, pp. 75-97. 